Research Article

\title{
Shear Capacity of Open Sandwich Steel Plate-Concrete Composite Slab: Experimental and Analytical Studies
}

\author{
Lili Wu $\mathbb{D}^{1,2}$ Lipei An, ${ }^{1,3}$ and Jiawei Li $\mathbb{D}^{1}$ \\ ${ }^{1}$ State Key Laboratory for Geomechanics and Deep Underground Engineering, China University of Mining and Technology, \\ Beijing 100083, China \\ ${ }^{2}$ School of Mechanics and Civil Engineering, China University of Mining and Technology, Beijing 100083, China \\ ${ }^{3}$ School of Civil Engineering, Hunan University, Hunan 410082, China \\ Correspondence should be addressed to Lili Wu; 314510706@qq.com and Jiawei Li; 270473511@qq.com
}

Received 19 March 2019; Revised 23 May 2019; Accepted 18 June 2019; Published 10 July 2019

Academic Editor: John Mander

Copyright ( 2019 Lili Wu et al. This is an open access article distributed under the Creative Commons Attribution License, which permits unrestricted use, distribution, and reproduction in any medium, provided the original work is properly cited.

Considering that the fixed crack model by default of the general finite element software was unable to simulate the shear softening behavior of concrete in the actual situation, a rotational crack model based on the modified compression field theory developed by UMAT (user material) of ABAQUS software was proposed and applied to the nonlinear analysis, and a numerical simulated model for the steel-concrete composite slab was built for shear analysis. Experimental studies and numerical analyses were used to investigate the shear load-carrying capacity, deformation, and crack development in steel plate-concrete composite slab, as well as the effects of the shear span ratio and shear stud spacing on the shear performance and the contribution of the steel plate and the concrete to the shear performance. Shear capacity tests were conducted on three open sandwich steel plate-concrete composite slabs and one plain concrete slab without a steel plate. The results indicated that the shear-compression failure mode occurred primarily in the steel plate-concrete composite slab and that the steel plate sustained more than $50 \%$ of the total shear force. Because of the combination effect of steel plate, the actual shear force sustained by the concrete in the composite slab was 1.27 to 2.22 times greater than that of the calculated value through the Chinese Design Code for Concrete Structures (GB 50010-2010). Furthermore, the shear capacity of the specimen increases by $37 \%$ as the shear stud spacing decreases from $250 \mathrm{~mm}$ to $150 \mathrm{~mm}$. By comparing the shear capacity, the overall process of load deformation development, and the failure mode, it was shown that the simulation results corresponded with the experimental results. Furthermore, the numerical simulation model was applied to analyze the influence of some factors on composite slab, and a formula of shear bearing capacity of slab was obtained. The results of the formula agreed with the test result, which could provide references to the design and application of steel plate-concrete composite slab.

\section{Introduction}

A steel plate-concrete composite component is a combination of steel and concrete (Figure 1). Anchor shear studs are welded onto a steel plate to connect the steel plate to a concrete slab.

Due to the simplicity of these structures, steel plateconcrete composite components, including composite beams, slabs, or shear walls, have been recently used for strengthening purposes $[1,2]$ and as components of steel plate-concrete composite shear walls [3-6]. Other applications of steel plate-concrete composite slab, such as in railway and subway bridge structures, are expected to emerge, such as bridge structures of railway viaducts $[7,8]$.

Link and Elwi [4] conducted an experimental study and numerical simulation of a dual-layer steel plate-concrete composite shear wall. The transverse and vertical loadcarrying capacity and ductility were analyzed, and the effect of the friction and contact between the steel plate and concrete was simulated. The results showed that it was easy to understand the behavior of the walls in light of failure modes, bearing mechanism, stress redistribution, and postpeak response. Takeuchi et al. [9] explored the performance of the steel plate-concrete composite shear walls 


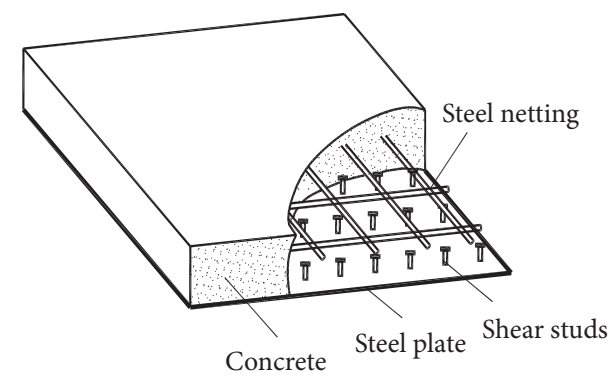

FIgURE 1: Steel plate-concrete composite component.

used in nuclear power plants by experiments, in which the bending and shear performance of the composite shear walls were analyzed. As demonstrated through the compression tests conducted in that study, local buckling of the steel plate had no influence on the load-carrying capacity of the steel plate-concrete composite shear wall. Liang et al. [10] developed a finite element analysis on the performance of a dual-layer steel plate-concrete composite shear wall subjected to compression and in-plane shear. The effects of the local buckling and spacing of the studs on the ultimate loadcarrying capacity of the composite shear wall were analyzed. The results indicated that when the height-to-thickness ratio of the composite shear wall was small, the ultimate loadcarrying capacity of the shear wall was determined by the shear bearing capacity of the shear studs and the local buckling capacity of the steel plate. Furthermore, when the height-to-thickness ratio of the composite shear wall was large, the shear wall was able to produce postbuckling strength. Varma et al. [11] put forward a mechanical model for a steel plate-concrete composite shear wall, which was primarily used to analyze the in-plane shear force and outof-plane bending moment. A composite wall designed to prevent failure modes such as shear damage at the related plane of action and local buckling of the steel plate was proposed. Arabzadeh et al. [12] conducted experimental studies of one- and three-story steel plate-composite shear walls with the scales of $1: 3$ and $1: 4$. Their results showed that bolt spacing to plate thickness ratio was directly related to system ductility, whereas the plate yield load decreased with the increase of the ratio. Through that study, plate stiffening requirements were obtained with minimum reinforcement for reinforced concrete. Arabzade et al. [13] analyzed the steel plate-composite shear walls through experimental and theoretical studies and addressed the buckling load of the steel plate. The elastic buckling coefficients of steel plates with various aspect ratios were obtained. Zhang et al. [14] studied steel plate-concrete composite walls used for nuclear power plants, consisting of thick concrete walls with exterior steel plates serving as reinforcement. Considering the significant influence on the behavior of steel-concrete composite walls, the shear connectors should be designed accordingly. The maximum steel plate slenderness (i.e., the ratio of shear connector spacing to plate thickness) to prevent local buckling was derived.

Some studies have focused on dual-layer steel plateconcrete composites. Yang et al. [15] studied open sandwich steel plate-concrete composite slabs, mostly focusing on bending performance. In practical engineering, open sandwich steel plate-concrete composite slabs have been widely used for composite strengthening and in railway bridges. The amount of shear load individually borne by the steel plate and concrete slab components of a single steel plate-concrete composite slab is not clear. Meanwhile, accurate indication of the effect of the material performance of the steel plate and concrete components and the degree of shear connection on the interface is urgently needed for shear strengthening projects.

At present, common finite element software incorporates a fixed crack model in numerical simulations by default. Application of a rotating crack model, which is more practical, requires secondary analysis by the finite element software, and there are few systematic studies in this aspect.

In this study, an experimental evaluation of the shear resistance of a simply supported open sandwich steel plateconcrete composite slab was conducted, using three steel plate-concrete composite slabs and one concrete slab. The effects of the shear span ratio and shear stud spacing on the shear performance of the composite slab, the damage mode and the mechanism of the shear failure of the steel plateconcrete composite slab, and the shear sustained individually by the steel plate and concrete were analyzed. A secondary analysis using the UMAT subprogram of ABAQUS was conducted, and the modified compression field theory (MCFT) was applied to analyze the shear capacity of the concrete. The experimental results were compared with the results of the numerical simulation in order to validate the model. Furthermore, the influence of some factors on composite slab was analyzed by the numerical simulation model and a formula of shear bearing capacity of slab was obtained, which could provide references to the design and application of steel plate-concrete composite slab.

\section{Experimental Program}

2.1. Specimen. Three steel plate-concrete composite slabs, identified as SCS-1, SCS-2, and SCS-3, were designed as shown in Figure 2 and the main parameters of each specimen are shown in Table 1. The shear stud spacing and shear span ratio, $\lambda(=a / h)$, where $a$ is the distance between the loading point and support point and $h$ is the height of the composite slab, varied among the different composite slabs. $b_{\mathrm{s}}$ is the thickness of the steel plate. All composite slabs had height of $400 \mathrm{~mm}$, thickness of $150 \mathrm{~mm}$, and distance between the support point and slab ends of $100 \mathrm{~mm}$.

The steel material used for the steel plate had the yield strength of $316.7 \mathrm{MPa}$, the ultimate strength of $448.8 \mathrm{MPa}$, and the percentage elongation of $28.8 \%$. The concrete used in the composite samples had the averaged compression strength of $28.66 \mathrm{MPa}$ based on three standard concrete cube specimens of $150 \times 150 \times 150 \mathrm{~mm}$. Shear studs, made of ML15 steel, had the diameter of $13 \mathrm{~mm}$ and the ultimate tensile strength of $f_{\text {us }}=400 \mathrm{MPa}$. For comparison, a plain concrete slab without a steel plate, identified as SCS-4, was cast using the same material and reinforcement as shown in Figure 2. 

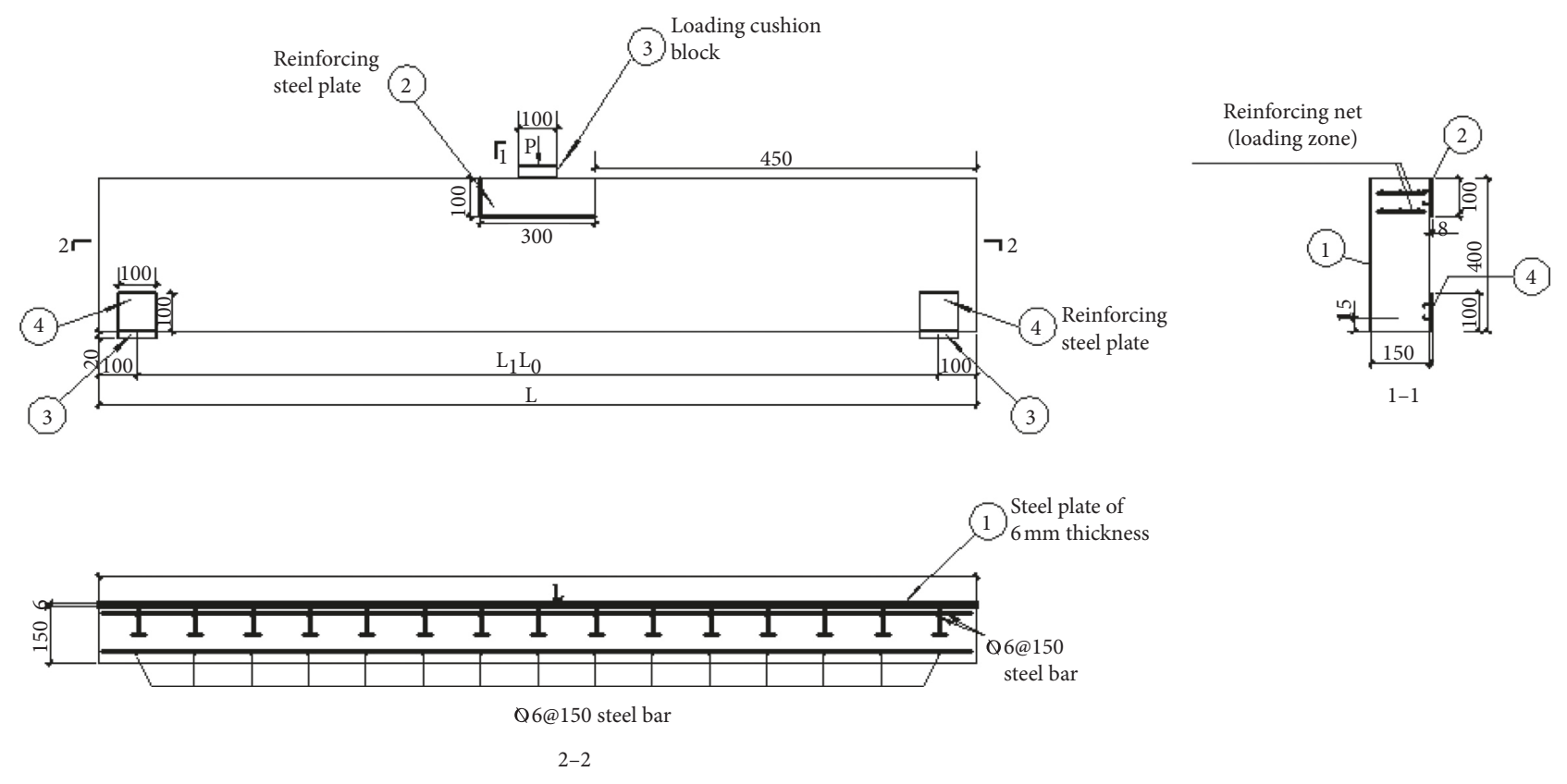

Figure 2: Sectional dimensions of specimens.

TABLe 1: Test matrix of steel plate-concrete composite deep slabs.

\begin{tabular}{|c|c|c|c|c|c|c|}
\hline Specimens & $\lambda$ & Span L0 $(\mathrm{mm})$ & $a(\mathrm{~mm})$ & bs $(\mathrm{mm})$ & Stud spacing $(\mathrm{mm})$ & Steel mesh $(\mathrm{mm})$ \\
\hline SCS-1 & 2.63 & 2100 & 1050 & 6 & 150 & $\Phi 6-150$ \\
\hline SCS-2 & 1.88 & 1500 & 750 & 6 & 150 & Ф6-150 \\
\hline SCS-3 & 1.88 & 1500 & 750 & 6 & 250 & Ф6-150 \\
\hline SCS-4 & 1.88 & 1500 & 750 & - & - & Ф6-150 \\
\hline
\end{tabular}

In order to demonstrate typical shear failure and prevent local damage at the loading zone and supports, two layers of steel mesh were placed at the loading zone, and small steel plates of $6 \mathrm{~mm}$ thick were placed on the sides of the concrete at the loading zone (short studs were welded at the inner surface).

2.2. Test Setup and Instruments. Three-point static loading tests were conducted on the four specimens. The ends of the specimens were simply supported. Cushion blocks were established at the midspan loading zones of the composite slabs to ensure that the vertical displacement of the steel plate and concrete at the loading zone remained identical, to sustain the load and prevent local damage at the loading zone together. Step loading which was driven by displacement was used according to the predicted failure load in order to measure the displacement and collect the strain value when the deformation was fully developed. The test setup is shown in Figure 3.

The test measurements included deflection at the midspan and $350 \mathrm{~mm}$ around it, transverse and side displacement of the support, and strain of each section. A labelled layout of the measuring points is provided in Figure 4, in which $H_{i}$ denotes the displacement gauges, $S_{i}$ denotes the strain gauges and the strain rosettes on the steel plate, and $C_{i}$ denotes the strain gauges on the concrete. Strain gauges were placed in the general area of both sides of the plain concrete slab and the steel plate.

\section{Test Results and Discussion}

3.1. Failure Mode. Vertical cracks were first observed at midspan when the loading force approached $40 \% P_{\mathrm{u}}$, where $P_{\mathrm{u}}$ is the peak load. These vertical cracks at midspan further propagated and widened with the increase of the applied load. When the loading force reached $85 \% P_{\mathrm{u}}$, diagonal shear cracks simultaneously appeared on the side of the concrete and peeling of the steel plate appeared near the loading area on the top. The pattern of the cracks is shown in Figure 5, where the number denotes the load at the time of crack development at the respective location.

As is evident from the damage to SCS-2 and SCS-3 when $\lambda \leq 2.0$, the mode of failure appears to be typical shearcompression failure. The failure process was rapid. The failure load and the load at the time of development of diagonal cracks were similar. The development of cracks in the diagonal section was more sudden, and the brittleness was more obvious in the specimen with smaller shear stud spacing. Due to the increased shear span ratio of specimens SCS-1 $(\lambda=2.63)$ and SCS- 4 , the concrete failure appeared to be bending one, and the concrete failure of SCS-4 was the result of the failure of the normal section of the bending member, which was sparsely reinforced. Therefore, the mode 


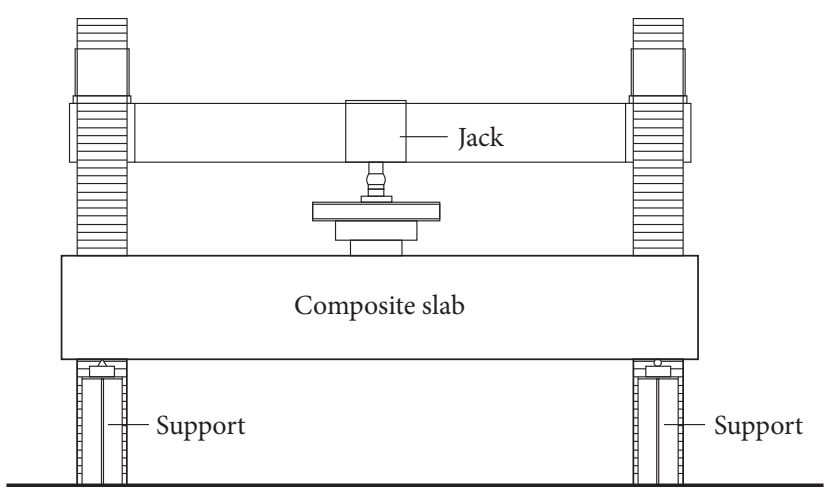

(a)

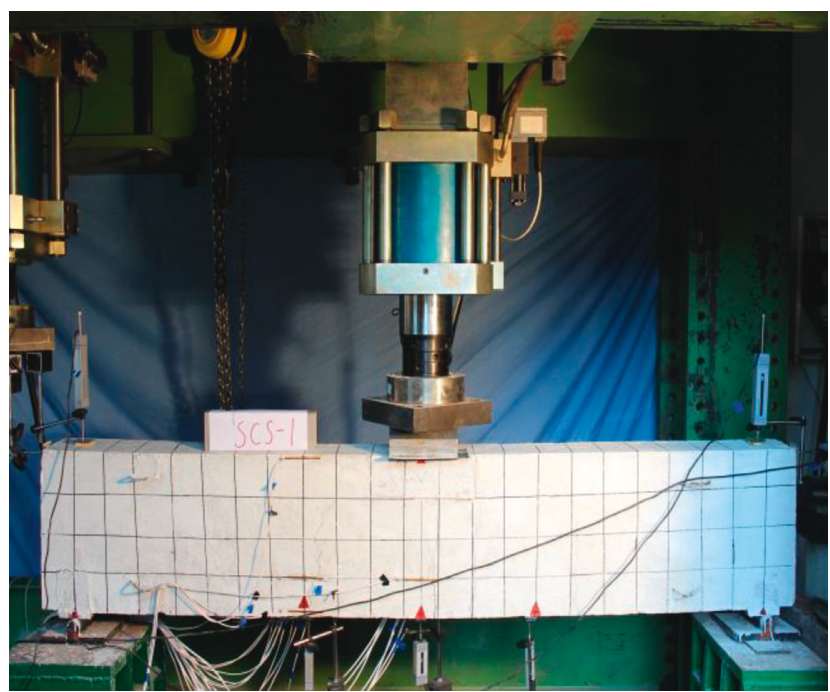

(b)

Figure 3: Test setup.

of failure of the steel plate-concrete composite slab was related not only to the shear stud spacing but also to the shear span ratio of the composite slab.

3.2. Load-Displacement Relations. The load-displacement relations of the three composite slabs and the plain concrete slab are shown in Figure 6, where the $x$-coordinate denotes the midspan deflection $\delta$ and the $y$-coordinate denotes the load of the specimen. As shown in Figure 6, the loading process of the steel plate-concrete composite slabs could be separated into three stages:

(a) Elastic stage: the stage lasted from the start of loading until the elastic shear capacity stage. All parts of the specimen were in the elastic state, and the relationship between the shear stress and midspan deflection was essentially linear for all specimens.

(b) Elastoplastic stage: when cracks appeared on the concrete, the stiffness of the specimen decreased and deflection development was accelerated. The loaddisplacement curve of the composite slab was nonlinear. Vertical cracks appeared on the concrete at the midspan and the cracks widened as the load increased. (c) Descending stage: as the load was continually increased, once a certain load-carrying capacity of the steel plate-concrete composite slab was reached, diagonal cracks appeared in the concrete. At this point, the load-carrying capacity was at its maximum and shear failure occurred at the side of the concrete. Due to the increase in shear span ratio and decrease in shear stud spacing, the descending branch of the curve was smooth. The three composite slabs demonstrated outstanding ductility compared to SCS-4.

3.3. Shear Capacity of the Specimens. In the Chinese Design Code for Concrete Structures (GB 50010-2010)), the reinforced concrete shear capacity, $V_{c}$, is stipulated by

$$
V_{\mathrm{c}}=\alpha_{\mathrm{cv}} f_{t} b h_{0} \text {, }
$$

where $\alpha_{\mathrm{cv}}=1.75 /(\lambda+1), \lambda$ is shear span ratio, $b$ and $h_{0}$ are, respectively, the width and effective height of the section. The contribution of the reinforcement mesh bars is ignored here.

All data, as well as test results, are summarized in Table 2. In this table, $P_{j}$ is the measured ultimate load value and $P_{\mathrm{js}}$ is the ultimate load sustained by the steel plate that can be 


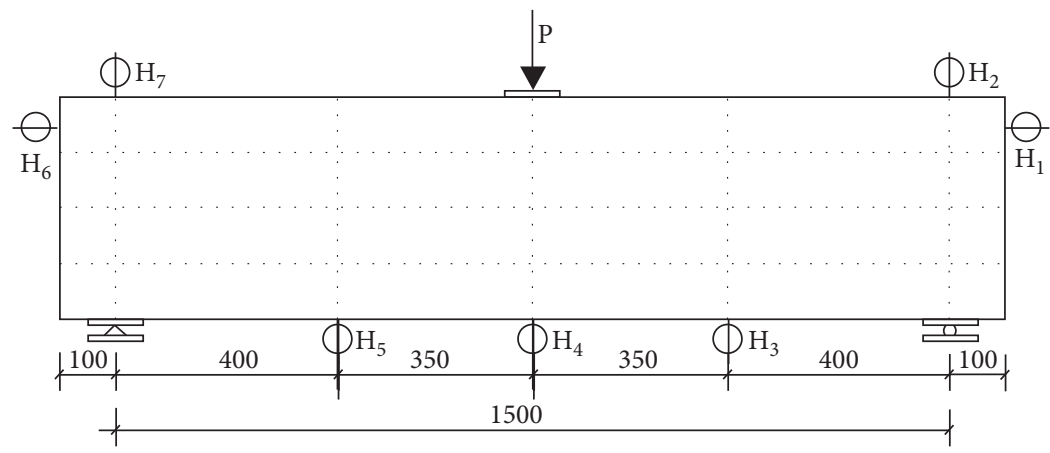

(a)

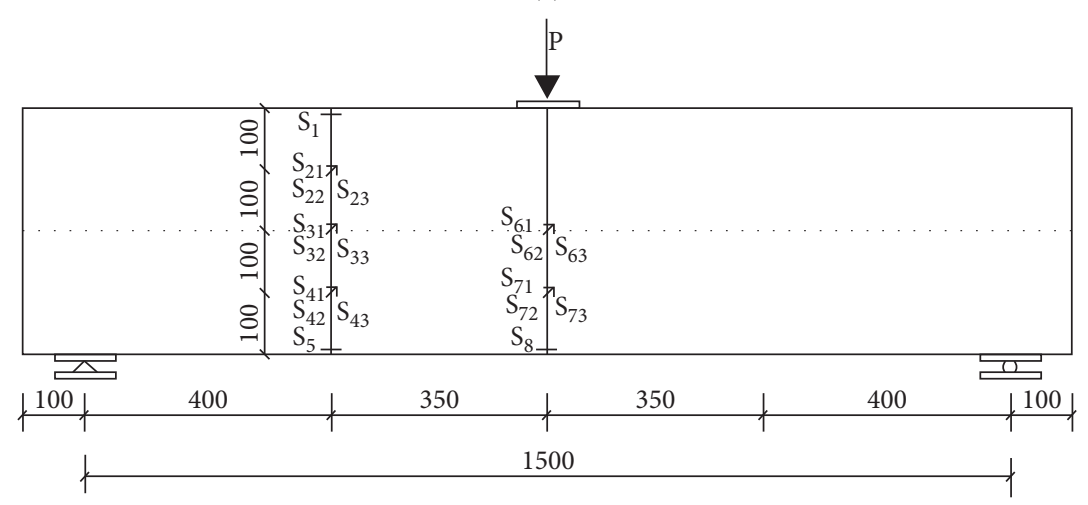

(b)

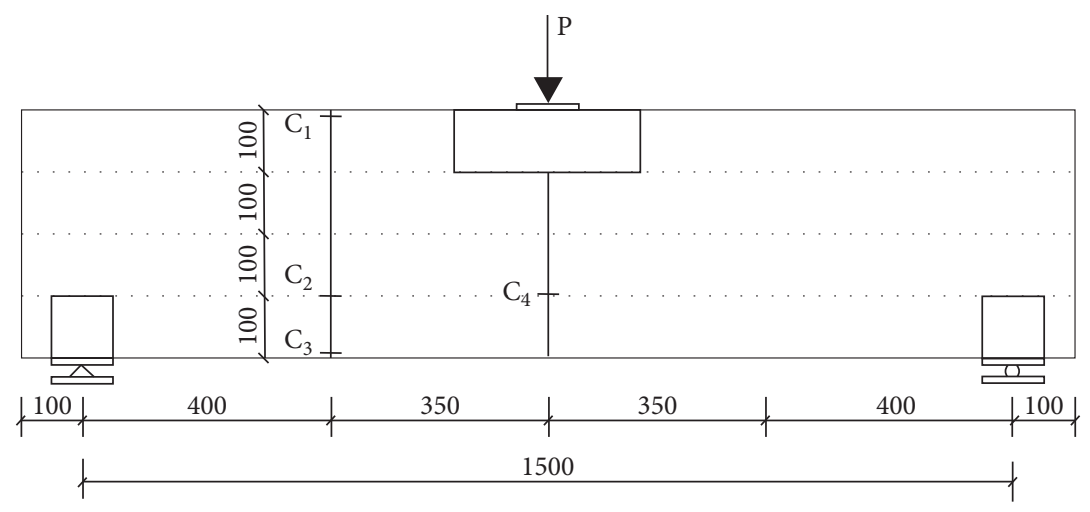

(c)

FIGURE 4: Layout of displacement gauges and strain gauges. (a) Layout of displacement gauges. (b) Layout of strain gauges on steel plate. (c) Layout of strain gauges on concrete slabs.

obtained by the strain gauges on the steel plate. Therefore, $P_{\mathrm{jc}}$ is the ultimate load sustained by the concrete that can be found by subtracting $P_{\text {is }}$ from $P_{j} . V_{c}$ is the ultimate load of the concrete calculated through the standard of the concrete. The ratio $P_{\mathrm{js}} / V_{\mathrm{c}}$ represents the strengthening function of the steel plates in the steel plate-concrete composite slabs for the concrete part.

The ultimate load sustained by the steel plate $P_{\text {js }}$ could be calculated from $\varepsilon_{1}, \varepsilon_{2}$, and $\varepsilon_{3}$ measured by the strain gauges on the steel plate. The strain analysis process for the steel plate was as follows. When the material was still elastic, two principal stresses $\sigma_{1}$ and $\sigma_{2}$ and the vertical stress $\tau_{x y}$ could be derived according to the mechanics of the material. The following formulas were obtained:

$$
\begin{aligned}
\sigma_{1,2} & =\frac{E\left(\varepsilon_{1}+\varepsilon_{3}\right)}{2(1-\nu)} \pm \frac{E}{2(1-\nu)} \sqrt{2\left(\varepsilon_{1}-\varepsilon_{2}\right)^{2}+2\left(\varepsilon_{2}-\varepsilon_{3}\right)^{2}}, \\
\tau_{x y} & =\frac{E}{2(1+\nu)}\left(\varepsilon_{1}+\varepsilon_{2}-2 \varepsilon_{3}\right) .
\end{aligned}
$$

According to the von Mises yield condition, when the material equivalent stress $\sigma_{n}$ (calculated by formula (4)) was greater than the material yield strength $f_{\mathrm{w}}$, the material came into the yield stage. On the basis of the incremental theory in plastic mechanics, when the material was in the plastic state, the expressions for calculating the two principal 

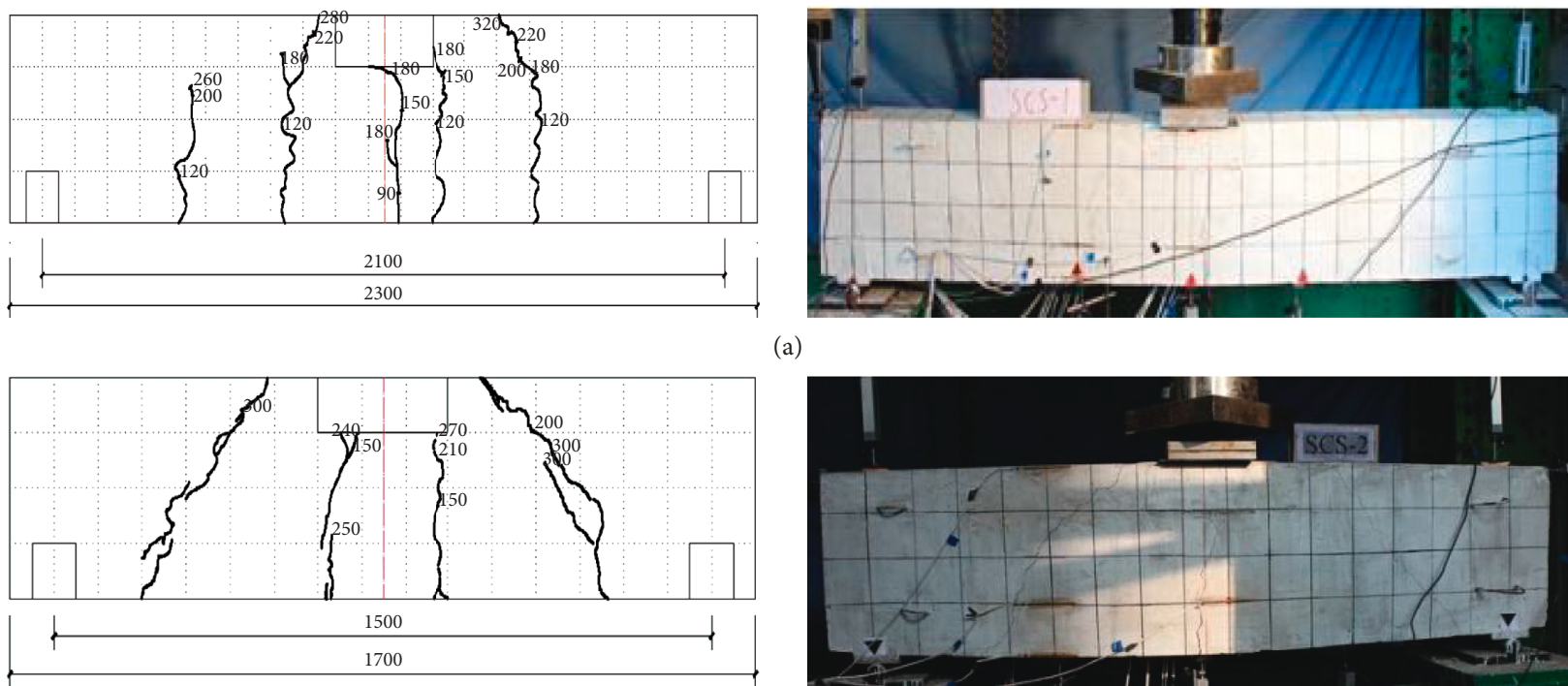

(a)

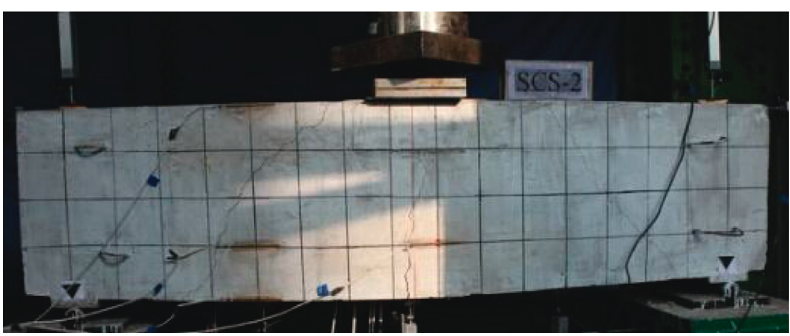

(b)
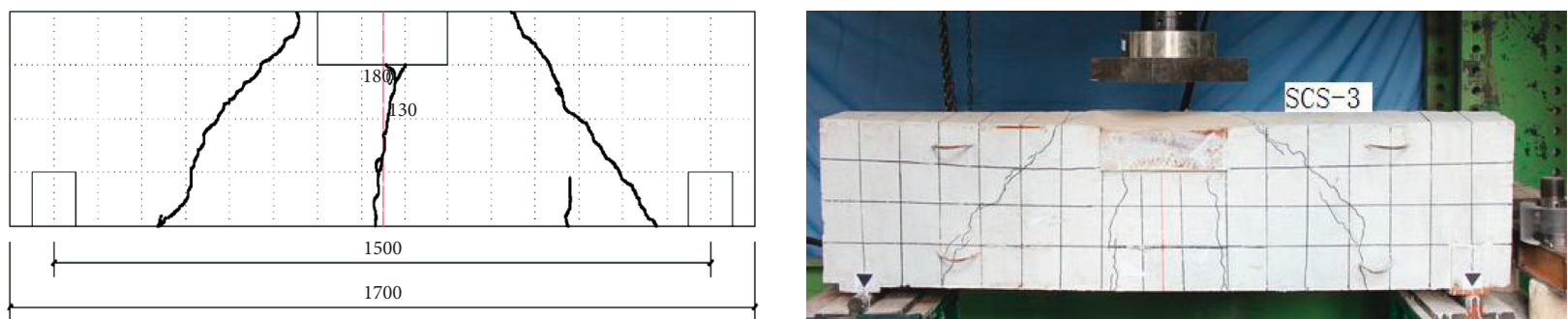

(c)
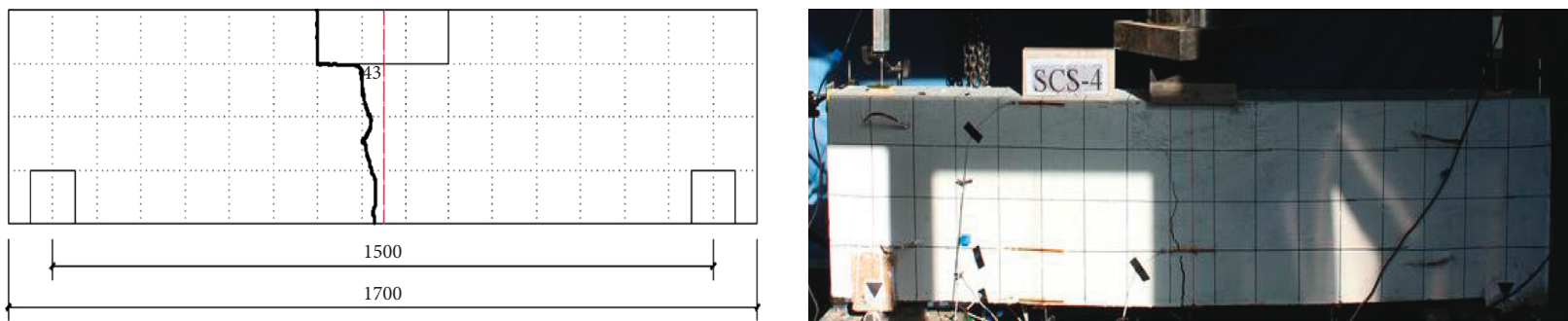

(d)

FIGURE 5: Crack pattern of steel plate-concrete composite slabs. (a) Crack pattern diagram for SCS-1 $(\lambda=2.63)$. (b) Crack pattern diagram for SCS-2 $(\lambda=1.88)$. (c) Crack pattern diagram for SCS-3 $(\lambda=1.88)$. (d) Crack pattern diagram for SCS-4 $(\lambda=1.88)$.

stresses and shear stress could be obtained from the following formulas:

$$
\begin{aligned}
& \sigma_{n}=\sqrt{\frac{1}{2}\left[\left(\sigma_{1}-\sigma_{2}\right)^{2}+\sigma_{1}^{2}+\sigma_{2}^{2}\right]}, \\
& \sigma_{1}^{\prime}=\frac{2 \beta+1}{\sqrt{3\left(\beta^{2}+\beta+1\right)}} f_{\mathrm{w}}, \\
& \sigma_{2}^{\prime}=\frac{\beta+2}{\sqrt{3\left(\beta^{2}+\beta+1\right)}} f_{\mathrm{w}}, \\
& \tau_{x y}^{\prime}=\frac{1}{2}\left(\sigma_{1}-\sigma_{2}\right) \sin \left(2 \alpha_{0}\right) .
\end{aligned}
$$

Table 2 indicates that the shear force sustained by the concrete ranged from approximately $37 \%$ to $47 \%$, and the steel plate contributed more than $50 \%$ of the shear capacity. As shown by comparison of SCS-1 and SCS-2, the ultimate shear capacity decreased as the shear span ratio increased. Furthermore, as shown by comparison of SCS-2 and SCS-3, the ultimate shear capacity decreased as the shear stud spacing increased. As evident from comparisons of SCS- 4 to SCS-1 and SCS-3, the steel plate improved the ultimate shear capacity of the composite slab and the loading capacity of the composite slab was three times greater than that of the plain concrete. The actual shear force sustained by the concrete in the composite slab was 1.27 to 2.22 times greater than that of the calculated value through the Chinese Design Code for Concrete Structures (GB 50010-2010). Moreover, the load- 


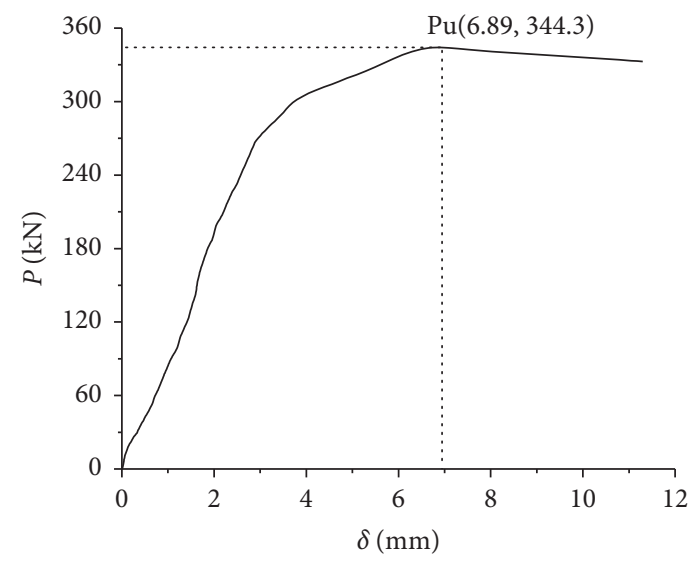

(a)

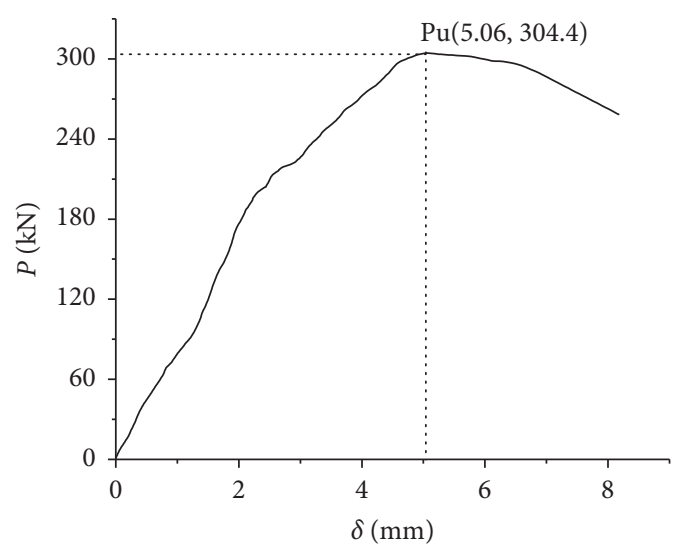

(c)

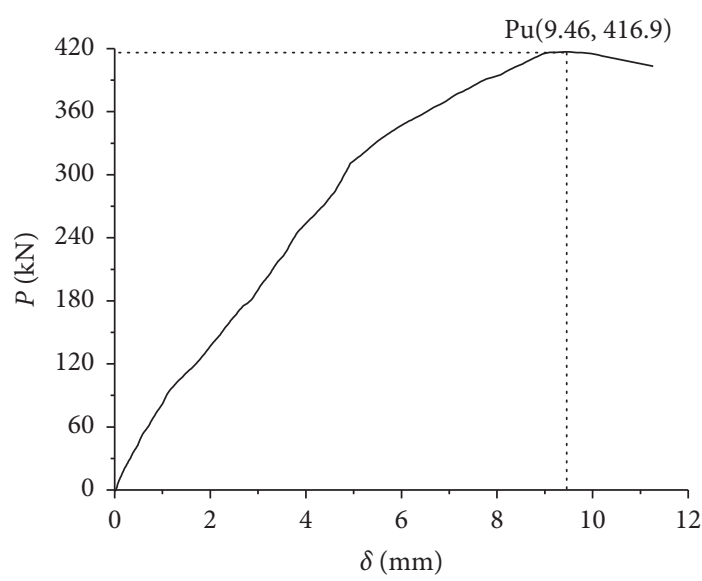

(b)

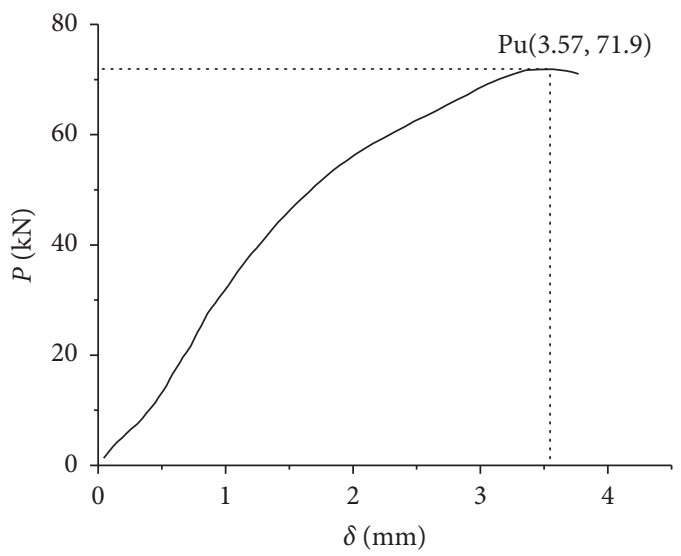

(d)

FIGURE 6: Load-displacement diagrams: (a) SCS-1, (b) SCS-2, (c) SCS-3, and (d) SCS-4.

TABLE 2: Experimental load value $(\mathrm{kN})$.

\begin{tabular}{lccccccc}
\hline Specimens & $\lambda$ & $P_{j}$ & $P_{\mathrm{jc}}$ & $P_{\mathrm{js}}$ & $P_{\mathrm{jc}} / P_{j}$ & $V_{\mathrm{c}}$ & $P_{\mathrm{jc}} / V_{\mathrm{c}}$ \\
\hline SCS-1 & 2.63 & 344.3 & 155.3 & 189.0 & 0.45 & 87.7 & 1.77 \\
SCS-2 & 1.88 & 416.9 & 195.0 & 221.9 & 0.47 & 87.7 & 2.22 \\
SCS-3 & 1.88 & 304.4 & 111.7 & 192.7 & 0.37 & 87.7 & 1.27 \\
SCS-4 & 1.88 & 71.9 & 71.9 & 0 & 1.0 & 87.7 & - \\
\hline
\end{tabular}

carrying capacity of the concrete was higher with smaller shear stud spacing. Bending failure with a low load-carrying capacity occurred in the plain concrete specimen, whereas the failure mode for the composite slabs was shear failure owing to the presence of the steel plate.

\section{Modeling of Shear Capacity of the Composite}

Numerical simulation using finite element analysis (FEA) was conducted to further explore the shear capacity of the composite. The commercially available FEA software ABAQUS was used in this study.

4.1. Material Properties of Steel Plate. A shell element, S4R, was used to simulate the steel plate, and a rectangular beam section element, B32, was used to simulate the concrete. Twenty-five integral points were placed in the beam section, and modified compression field theory was applied to each integral point. The constitutional relationship was defined by a bilinear elastic hardening model (bilinear model). The yield strength and elastic modulus were given according to the experimental results given in Section 2.1 Young's modulus of the steel was $194 \mathrm{GPa}$, and Poisson's ratio was 0.3 .

\subsection{Material Properties of Concrete Using Fixed Crack Model} and Rotation Crack Model. Here, two models were used to simulate the concrete cracking: (a) the rotation crack model using the developed UMAT subprogram of the concrete rotation crack model (denoted as RCM) and (b) a fixed crack model (denoted as FCM), which is presented in the next section.

4.2.1. Fixed Crack Model. According to the fixed crack model, the direction of the cracks that appeared after the first was identical to that of the first. In other words, the shear stress at the crack surface increased until shear locking occurred. In practice, crack direction angles vary as the load increases, and the shear stress at the crack surface remains steady or even decreases. However, the fixed crack model cannot simulate the shear softening problem of concrete in practical situations and it overestimates the analytical result of shear capacity. The rotation crack model can demonstrate 
the variation in angle direction, as presented in the next section. The stiffness matrix can vary at any time under different crack directions, and the shear stress at the crack surface can be better simulated.

\subsubsection{Rotation Crack Model Using Modified Compression} Field Theory. Vecchio and Collins proposed the MCFT [16] based on compression field theory $[17,18]$. This theory suggests that when a crack appears in concrete, the principal tensile stress exists on the crack's surface and the shear force is sustained by both principal tensile and compressive stresses of the concrete. The equilibrium condition, deformation compatibility condition, and constitutional condition (including the compressive and tensile constitution of the concrete) are established according to the mean stress and strain values. Thereby, the shear strength of reinforced concrete can be better represented.

The UMAT in ABAQUS was used to define the subroutine of the MCFT for describing the rotation crack model for the concrete. When the state variant and strain increment were input by the main program, the UMAT solved the stress increment according to the strain variant, solved and returned the Jacobian matrix to develop the global stiffness matrix, and then temporarily stored the state variant for the next increment. The key was to solve the Jacobian matrix.

Because the coordinates and positive direction were different before and after the appearance of cracks in the concrete, the Jacobian matrix was also different. When $\varepsilon_{1} \leq \varepsilon_{\mathrm{cr}}$, where $\varepsilon_{1}$ is the principal tensile strain, $\varepsilon_{\mathrm{cr}}$ refers to the cracking strain, the uniaxial tensile stress of concrete is equal to the value before cracking, and the shear modulus of concrete is represented by $G=\left(f_{1}-f_{2}\right) / 2\left(\varepsilon_{1}-\varepsilon_{2}\right)$, as recommended by Zhu et al. [19]. The derived stiffness matrix $D_{c}$ is shown in equation (8); when $\varepsilon_{1}>\varepsilon_{\text {cr }}$, the uniaxial tensile stress is equal to the value after cracking, and the other parameters are not varied. According to the transformation of coordinates, the transformation matrix $T(\theta)$ is obtained in equation (9) and the stiffness matrix $D_{c}^{\prime}$ after the appearance of cracks is shown in equation (10). In these formulas, $f_{1}$ is the average tensile stress, $f_{2}$ is the average compressive stress, $\varepsilon_{2}$ is the principal compressive strain, $\theta$ is the directional angle of principal strain, $\nu_{12}$ is the average shear stress in the 1-2 coordinate, and $\gamma_{12}$ is the average shear strain in the 1-2 coordinate

$$
\begin{gathered}
D_{c}=\frac{\partial\{\sigma\}}{\partial\{\varepsilon\}}=\left\{\begin{array}{ccc}
\frac{\partial f_{1}}{\partial \varepsilon_{1}} & \frac{\partial f_{1}}{\partial \varepsilon_{2}} & \frac{\partial f_{1}}{\partial\left(\gamma_{12} / 2\right)} \\
\frac{\partial f_{2}}{\partial \varepsilon_{1}} & \frac{\partial f_{2}}{\partial \varepsilon_{2}} & \frac{\partial f_{2}}{\partial\left(\gamma_{12} / 2\right)} \\
\frac{\partial \nu_{12}}{\partial \varepsilon_{1}} & \frac{\partial \nu_{12}}{\partial \varepsilon_{2}} & \frac{\partial \nu_{12}}{\partial\left(\gamma_{12} / 2\right)}
\end{array}\right\}, \\
T(\theta)=\left[\begin{array}{ccc}
\cos ^{2} \theta & \sin ^{2} \theta & 2 \sin \theta \cos \theta \\
\sin { }^{2} \theta & \cos ^{2} \theta & -2 \sin \theta \cos \theta \\
-\sin \theta \cos \theta & \sin \theta \cos \theta & \cos ^{2} \theta-\sin ^{2} \theta
\end{array}\right],
\end{gathered}
$$

$$
D_{c}^{\prime}=T(-\theta) D_{c} T(\theta) .
$$

The detailed framework of the program is shown in Figure 7. As to belonging to nonlinear physical properties, the Newton-Raphson method was used in the iteration calculation process. The iterative convergence criterion was based on force, and the convergence tolerance was set to the default values in the software.

In accordance with the MCFT, the cracked concrete was treated as a new type of material. The reinforcement and cracks were smeared within the material so that no crack existed. The MCFT model used in this study required modification in order to cancel crack detection. The constitutional relationship of the MCFT was used as the compressive constitutional relationship of the concrete; the tensile constitutional relationship is represented by equations (11) and (12) in accordance with the modification of coefficient due to the cancellation of crack detection.

The tensile stress-strain relationship of concrete is written as

$$
\begin{array}{ll}
f_{\mathrm{cl}}=E_{\mathrm{c}} \varepsilon_{1}, & \varepsilon_{1} \leq \varepsilon_{\mathrm{cr}}, \\
f_{\mathrm{cl}}=\frac{f_{\mathrm{cr}}}{1+\sqrt{200 \varepsilon_{1}}}, & \varepsilon_{1}>\varepsilon_{\mathrm{cr}},
\end{array}
$$

where $E_{\mathrm{c}}$ is the elastic modulus of concrete, $f_{\mathrm{cl}}$ is the principal tensile stress, $f_{\mathrm{cr}}$ is the cracking stress, $\varepsilon_{1}$ is the principal tensile strain, and $\varepsilon_{\mathrm{cr}}$ is the cracking strain.

4.3. Modeling of Steel-Concrete Interface. The stud was the connecting element between steel plate and concrete. The relative slippage of the steel plate and concrete should be taken into account when modeling with ABAQUS software. Therefore, a nonlinear spring element was used to simulate the role of studs. The spring element adopted the shear slip formula for the slip curve proposed by Ollgaard et al. [20], as shown in the following formulas:

$$
\begin{array}{r}
V_{\mathrm{u}} \& 9 ;=0.43 A_{\mathrm{s}} \sqrt{E_{\mathrm{c}} f_{\mathrm{c}}} \leq 0.7 A_{\mathrm{s}} f_{\mathrm{u}}, \\
V \& 9 ;=V_{\mathrm{u}}\left(1-e^{-n s}\right)^{m},
\end{array}
$$

where $V$ is the shear force of the stud, $f_{\mathrm{u}}$ is the ultimate tensile strength of the stud, $V_{\mathrm{u}}$ is the ultimate shear capacity of the stud, $E_{\mathrm{c}}$ is the elastic modulus of concrete, $f_{\mathrm{c}}$ is the compressive strength of concrete, $s$ is the slippage, $m$ and $n$ are the shear correlation coefficients, and the selected values in this paper are $m=0.558, n=1 \mathrm{~mm}^{-1}$.

\section{Results and Discussion of Numerical Simulation}

5.1. Calibration of Numerical Simulation Using the Shear Capacity of Experimental Results. The steel plate-concrete composite slabs were modeled, and the boundary condition was established as a simple support at both ends. Loading was controlled through displacement. The finite element model of the composite slab is shown in Figure 8. 


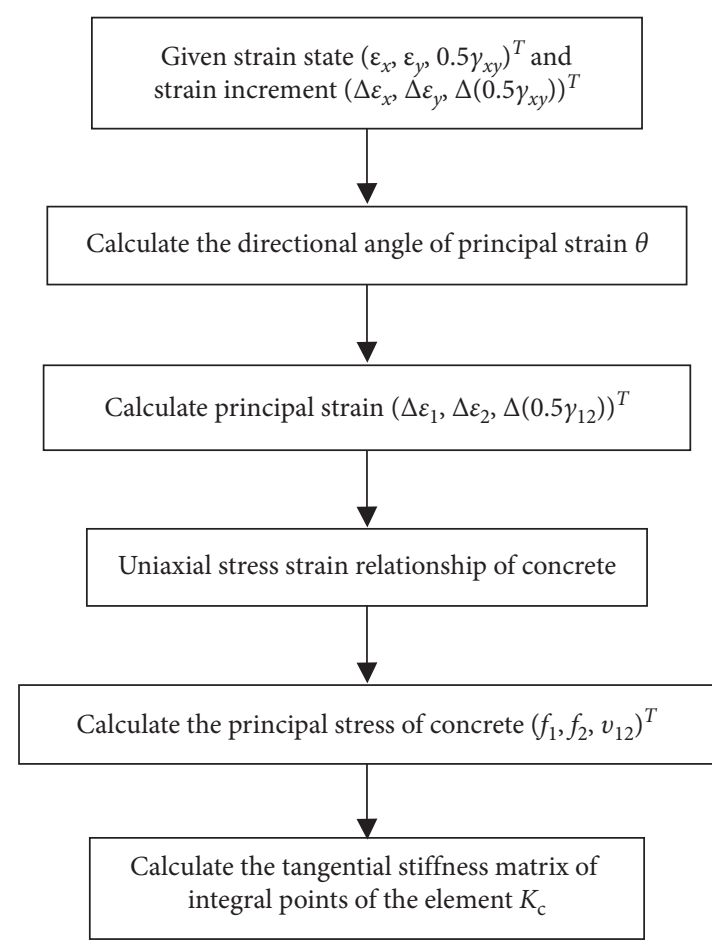

FIGURE 7: Flowchart of the rotation crack modeling using ABAQUS subroutine.

The results of simulation and the experimental data are listed in Table 3, in which $P_{j}$ is the experimental shear capacity, $P_{\mathrm{R}}$ is the shear capacity calculated by the RCM, and $P_{\mathrm{F}}$ is the shear capacity calculated by the FCM. As shown in Table 3, in comparison to the results obtained by the FCM, the shear capacity acquired by the RCM better matches that in the experimental results, validating the selection of the element and material properties of the shear model of the steel plate-concrete composite slab. The analytical shear capacity results were larger than the experimental results when the default concrete fixed crack model in ABAQUS was directly applied. The errors were equal to $8.7 \%, 9.5 \%$ $15.3 \%$, and $40.2 \%$ for each specimen, with SCS- 4 having the largest error. This was due to the use of the default fixed crack model in ABAQUS.

5.2. Load-Displacement Relations. Figure 9 shows the loaddisplacement diagram during the numerical calculation and experimental process. It also demonstrated that the analytical results obtained by the RCM fitted the experimental curve better than the results obtained by the FCM, suggesting that the rotation crack model secondarily developed from ABAQUS was more suitable for the analysis of the steel plate-concrete composite slab shear capacity.

\section{Formula of Shear Bearing Capacity}

From test analysis of Section 3, it could be concluded that the shear bearing capacity of the composite was related to several parameters, such as shear span ratio $\lambda$, steel plate

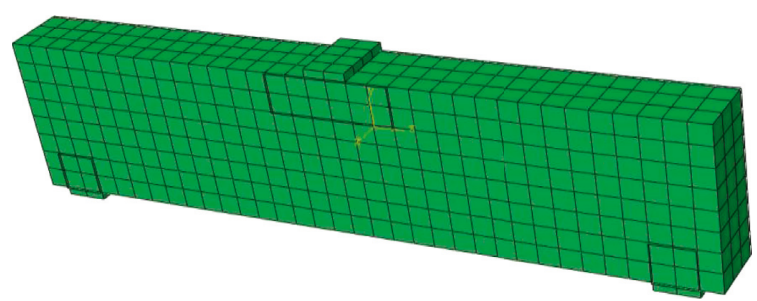

Figure 8: FEM model of composite slab.

TABle 3: Comparisons of shear capacity.

\begin{tabular}{lcccccc}
\hline Specimens & $\lambda$ & $P_{j}(\mathrm{kN})$ & $P_{\mathrm{R}}(\mathrm{kN})$ & $P_{\mathrm{F}}(\mathrm{kN})$ & $P_{\mathrm{R}} / P_{j}$ & $P_{\mathrm{F}} / P_{j}$ \\
\hline SCS-1 & 2.63 & 344.3 & 336.6 & 374.4 & 0.98 & 1.09 \\
SCS-2 & 1.88 & 416.9 & 408.6 & 456.6 & 0.98 & 1.10 \\
SCS-3 & 1.88 & 304.4 & 299.4 & 350.8 & 0.98 & 1.15 \\
SCS-4 & 1.88 & 71.9 & 67.2 & 100.8 & 0.93 & 1.40 \\
\hline
\end{tabular}

thickness $t$, steel yield strength $f_{\mathrm{ys}}$, concrete strength $f_{\mathrm{c}}$, concrete thickness $b$, and section height $h_{0}$. Exclusion of the material property influence of steel yield strength $f_{\mathrm{ys}}$ and concrete strength $f_{c}$ (material properties), the parametric analysis of shear capacity of steel plate-concrete composite slabs was carried out using the FEA model on shear span ratio, steel plate thickness, concrete thickness, and shear stud spacing. Then, based on the formula of shear capacity of ordinary concrete beams, a formula of shear bearing capacity of composite slabs was proposed.

\subsection{Parametric Analysis}

6.1.1. Shear Span Ratio $\lambda$. The shear span ratio $\lambda=a / h$ was affected by shear span length $a$ and section height $h$. Therefore, the shear span ratio could be changed by the length of shear span or section height. In the analysis, the yield strength of steel plate is $235 \mathrm{MPa}$. The shear stud diameter is $13 \mathrm{~mm}$, and the shear stud spacing is $150 \mathrm{~mm}$. The strength of concrete is $30 \mathrm{MPa}$, and the concrete thickness is $150 \mathrm{~mm}$. Firstly, the influence of shear span length was considered: the height of the composite is $400 \mathrm{~mm}$ and the length of the composite is $1400 \mathrm{~mm}$, $1600 \mathrm{~mm}, 1800 \mathrm{~mm}, 2000 \mathrm{~mm}$ and $2200 \mathrm{~mm}$, respectively, to gain different shear span ratio. Figure 10(a) showed the effect of shear span length on shear capacity, in which the $x$ axis $a$ is the length of shear span and the $y$-axis $P$ is the shear bearing capacity. On the other hand, under the condition that the span remained unchanged, different shear span ratios were obtained by taking the section height of $400 \mathrm{~mm}, 450 \mathrm{~mm}, 500 \mathrm{~mm}$, and $550 \mathrm{~mm}$, respectively. Figure 10(b) showed the relationship between the section height and shear capacity. However, considering the stability of the composite slabs, the height of the composite should be limited within $600 \mathrm{~mm}$.

From Figure 10(a), with the increase of the shear span length, the shear capacity showed a relatively gentle downward trend, indicating that the shear span had little effect on the shear capacity of the composite. With the 


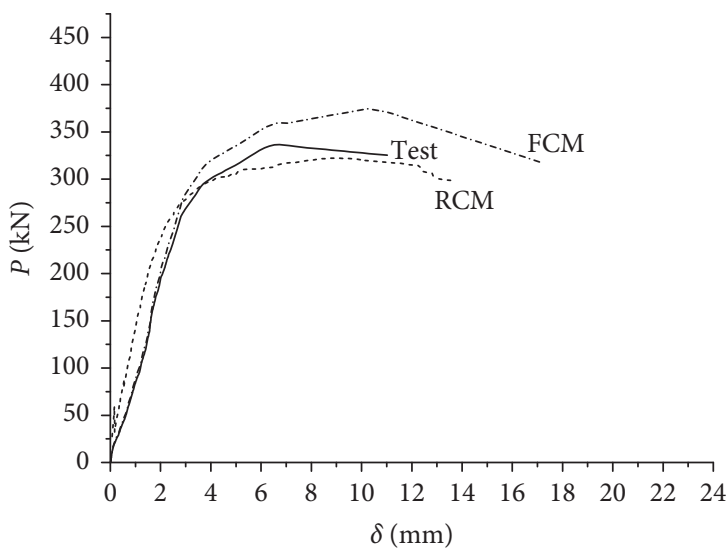

(a)

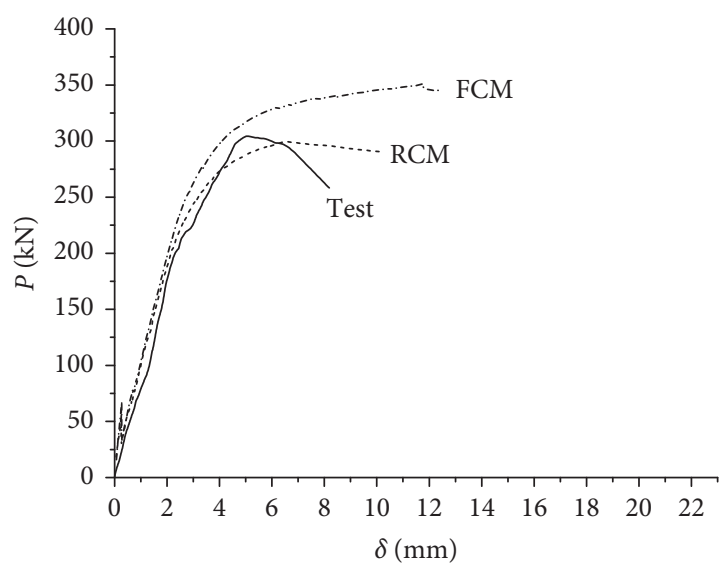

(c)

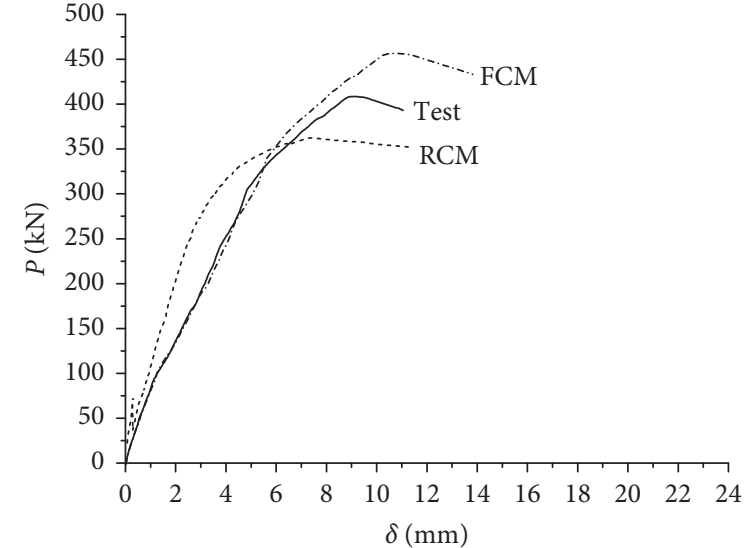

(b)

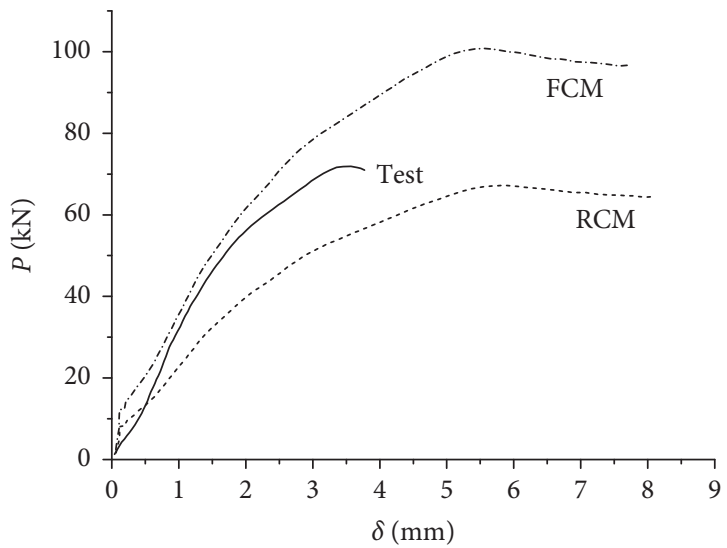

(d)

Figure 9: Comparison of experimental load-displacement curve to that of FEM: (a) SCS-1, (b) SCS-2, (c) SCS-3, and (d) SCS-4.

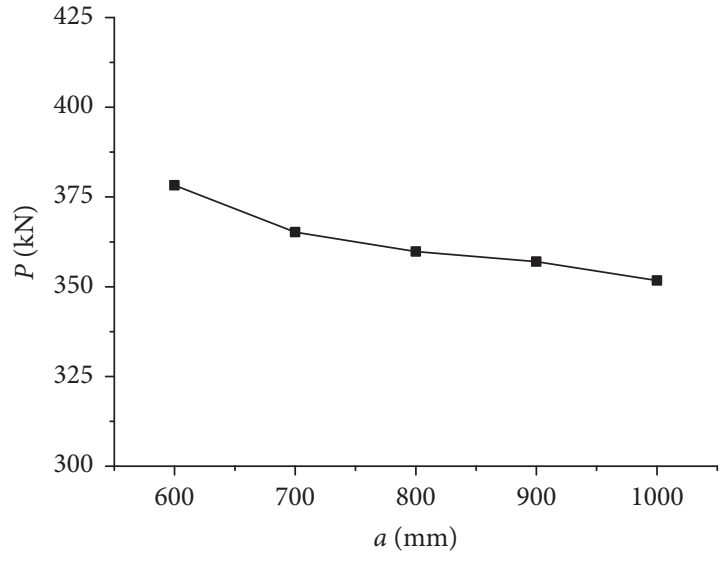

(a)

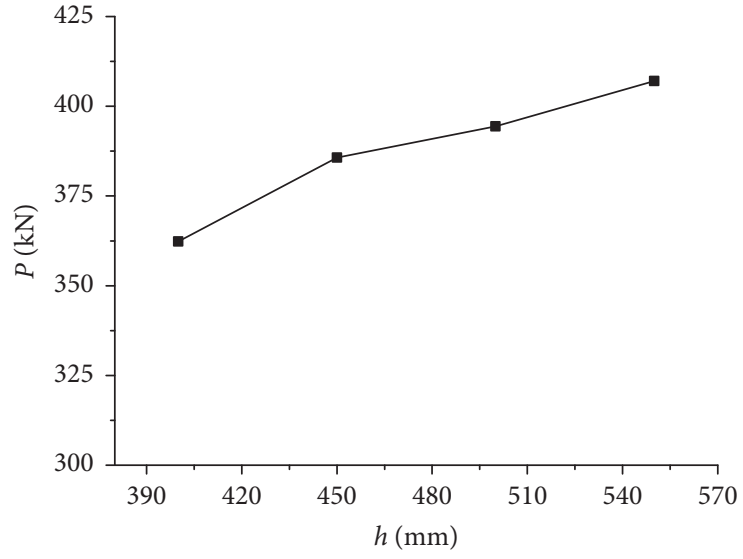

(b)

FIGURE 10: Relationship between shear span ratio and shear capacity. (a) Length of shear span. (b) Section height.

increase of section height, the shear capacity showed a more significant upward trend, as shown in Figure 10(b). The comparison between the above two cases showed that the influence of section height on shear span ratio was more obvious.
6.1.2. Steel Plate Thickness $t$. Based on the parameters in Section 6.1.1, with that the other parameters remained unchanged, the height and length of the composite were given as $400 \mathrm{~mm}$ and $1700 \mathrm{~mm}$, respectively. Then, the thickness of steel plate was changed from $6 \mathrm{~mm}$ to $14 \mathrm{~mm}$, in 
order to analyze the effect of steel plate thickness on the shear bearing capacity of steel plate-concrete composite slabs. The results are shown in Figure 11, in which the $x$-axis $t$ is the thickness of steel plate and the $y$-axis $P$ is the shear bearing capacity. The thickness $t$ of steel plate was proportional to the shear capacity of composite slabs, and this parameter was one of the important factors affecting the ultimate shear capacity of steel plate-concrete composite slabs, as shown in Figure 11. The shear capacity of steel plate was an integral part of the shear capacity of composite slabs.

6.1.3. Concrete Thickness $b$. As mentioned above, the shear bearing capacity of steel plate-concrete composite slabs was similar to combination of the respective shear resistance of steel plate and concrete, so concrete thickness $b$ was also an important factor of shear capacity. Based on the parameters of SCS-2 and under the condition of keeping other parameters unchanged, the concrete thickness $b$ was given as $110 \mathrm{~mm}, 120 \mathrm{~mm}, 130 \mathrm{~mm}, 140 \mathrm{~mm}$, and $150 \mathrm{~mm}$, respectively. Then, the relationship between the concrete thickness $b$ and the shear capacity was obtained, as shown in Figure 12. The $x$-axis $b$ is the concrete thickness, and the $y$ axis $P$ is the shear capacity. From the graph, the concrete thickness showed a significant proportional relationship with the shear capacity of the composite slabs, and it could be inferred that the concrete thickness was also one of main factors affecting the shear capacity.

6.1.4. Shear Stud Spacing $d$. In model test, the difference between SCS- 2 and SCS-3 was the shear stud spacing $d$. Therefore, in order to better consider the influence of studs, the relationship between the stud spacing $d$ and shear capacity of the composite was studied. The results are shown in Figure 13, in which the $x$-axis $d$ is the stud spacing and the $y$-axis $P$ is the shear capacity of the composite slabs. Based on the model test, the stud spacing was given as $150 \mathrm{~mm}, 250 \mathrm{~mm}, 450 \mathrm{~mm}$, and $500 \mathrm{~mm}$, respectively. From the graph, it could be concluded that the shear bearing capacity decreased slowly with the increase of stud spacing, so the stud spacing only had a small effect on the shear capacity of the composite slabs.

In the finite element analysis, considering the slip effect between steel plate and concrete slab, the nonlinear springs were used to simulate the stud. Figure 14 is the displacement diagram obtained by finite element simulation. It showed that the slip between steel plate and concrete slab of the three components was small, and the increase of stud spacing had little effect on the slip. It could be seen from the above analysis that the studs not only made the steel plate and concrete slabs work together as a whole but also played an important role in improving the shear bearing capacity of the composite by combing the two materials, but the stud spacing did not affect a lot to the shear bearing capacity of the integrity of component.

\subsection{Formula of Shear Bearing Capacity}

6.2.1. Formula Derivation. Through the parameter analysis of steel plate-concrete composite slab, the main factors of

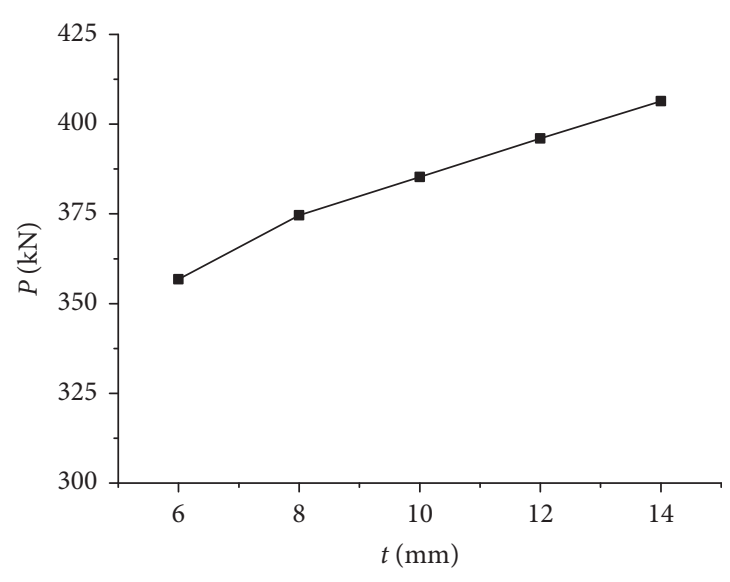

FIGURE 11: Relationship between steel plate thickness and shear capacity.

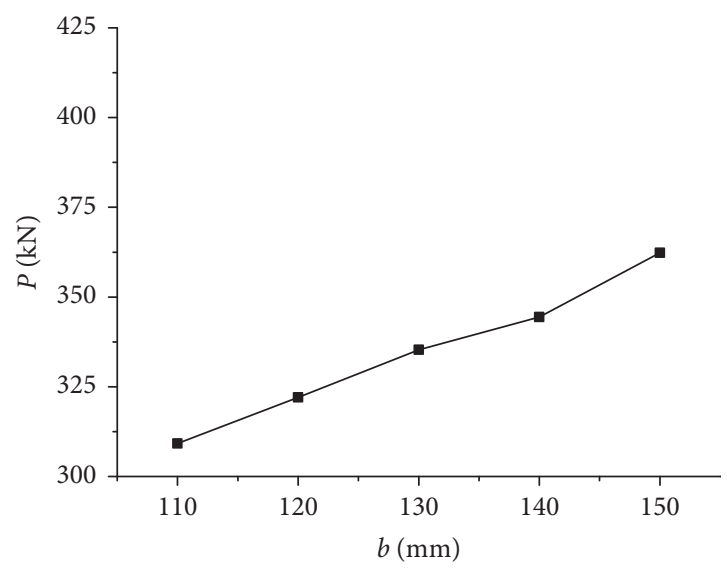

FIgURE 12: Relationship between concrete thickness and shear capacity.

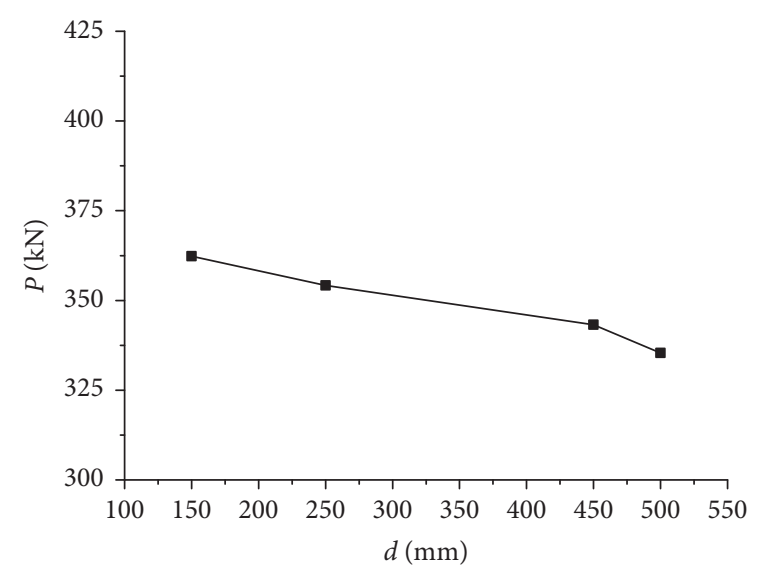

FIGURE 13: Relationship between shear stud spacing and shear capacity.

shear capacity were steel plate thickness $t$, concrete thickness $b$, and section height $h$. Moreover, the shear capacity of composite slabs was proportional to steel plate thickness $t$ and concrete thickness $b$ and inversely proportional to 


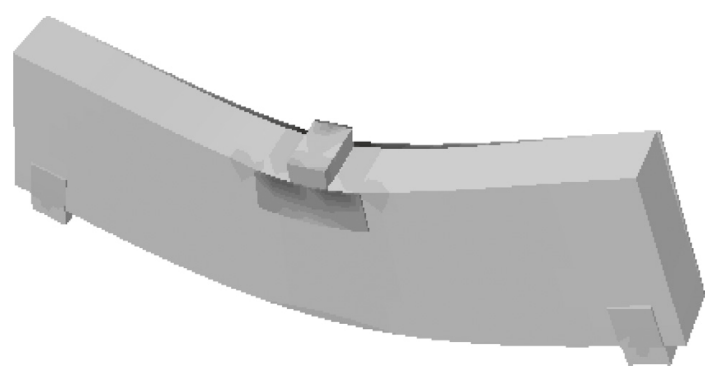

(a)

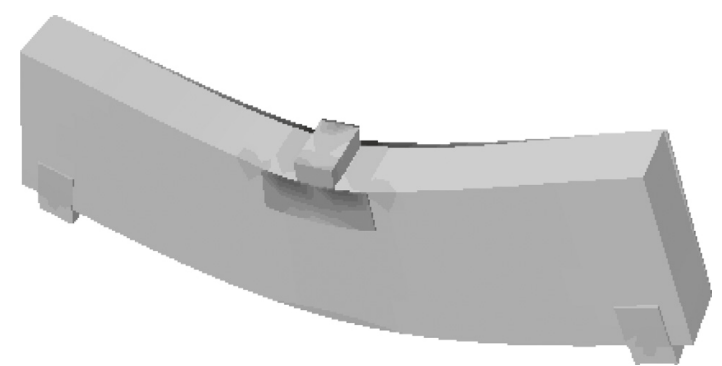

(b)

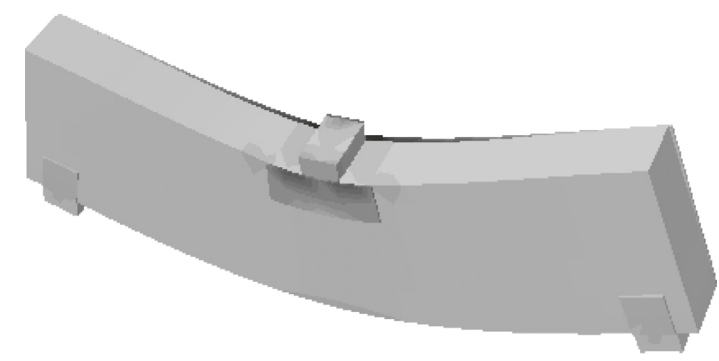

(c)

FIgURE 14: Deformation figure of composite slab under different stud spacings: (a) $150 \mathrm{~mm}$, (b) $250 \mathrm{~mm}$, and (d) $500 \mathrm{~mm}$.

section height $h$, which coincided with the interfering factors of shear capacity of steel plate and concrete slabs. Therefore, based on the shear bearing capacity formula of ordinary reinforced concrete beams, the shear bearing capacity formula of steel plate-concrete composite slabs was expressed as the sum of the bearing capacity of two materials, as shown in the following formula:

$$
V_{\mathrm{u}}=m f_{\mathrm{c}} b h+n f_{\mathrm{sy}} t h
$$

where $b$ is the concrete thickness, $h$ is section height, $t$ is the steel plate thickness, and $m, n$ are the combination coefficient of shear capacity of concrete and steel plate to be derived, respectively. The combination coefficients $m$ and $n$ should be determined by regression analysis. Considering that the section heights of steel plate and concrete slab were equal, the formula of shear bearing capacity could be changed into formula (16), in which the section height of component was proportional to the influence of the whole component. So, the effect of section height could not be considered in the regression analysis of combination coefficient.

$$
\frac{V_{\mathrm{u}}}{h}=m f_{\mathrm{c}} b+n f_{\mathrm{sy}} t
$$

(1) The Combination Coefficient $m$. When the parameters of steel plate were unchanged, only one parameter of concrete slab was changed: the concrete thickness $b$. According to the changes of this parameter, the influence on the shear capacity of composite slabs was analyzed, and then the combination coefficient of concrete was deduced. Six sets of example parameters are shown in Table 4. The relationship between the product of concrete thickness $b$ and concrete strength $f_{\mathrm{c}}$ and $V_{\mathrm{u}} / h$ was obtained by mechanical analysis, as shown in Figure 15, and then the combination coefficient could be obtained by further fitting analysis: $m=0.1956$.

(2) The Combination Coefficient $n$. When only the parameters of steel plate were changed, the combination coefficient of the steel plate was obtained by calculating some typical examples according to the change of the steel plate thickness $t$. Six sets of example parameters are shown in Table 5. The relationship between the product of steel plate thickness $t$ and steel yield strength $f_{\text {sy }}$ and $V_{\mathrm{u}} / h$ was obtained by mechanical analysis, as shown in Figure 16, and then the combination coefficient could be obtained by further fitting analysis: $n=0.1008$.

Based on the fitting curve of the above parameters, the general formula of shear bearing capacity of steel plateconcrete composite slabs proposed in this paper is shown in the following equation:

$$
V_{\mathrm{u}}=0.1956 f_{\mathrm{c}} b h+0.1008 f_{\mathrm{sy}} t h .
$$

The limitation of formula (17) includes that the section height is $h<600 \mathrm{~mm}$ and the span is $L<2300 \mathrm{~mm}$.

6.2.2. Verification of Formula. Considering the influence on practical engineering application, the general formula of shear bearing capacity of steel plate-concrete composite slabs obtained in the preceding section needed to be validated on the basis of test data. Based on the test data of three composite slabs, the results of model test and the results obtained by the shear capacity formula (equation (17)) were compared, as shown in Table 6. It could be seen that the results obtained by the shear capacity formula in this paper agreed with the test data by comparison, which 
TABLE 4: The parameters of the example.

\begin{tabular}{cccccc}
\hline$h(\mathrm{~mm})$ & $t(\mathrm{~mm})$ & $f_{\mathrm{c}}(\mathrm{MPa})$ & $f_{\text {sy }}(\mathrm{MPa})$ & $b(\mathrm{~mm})$ & $V_{\mathrm{u}}(\mathrm{kN})$ \\
\hline & & & & 150 & 335.63 \\
& & & & 140 & 321.86 \\
400 & \multirow{3}{*}{6} & \multirow{2}{*}{20.1} & \multirow{2}{*}{235} & 130 & 295.65 \\
& & & & 120 & 287.34 \\
& & & & 110 & 273.21 \\
& & & & 100 & 256.39 \\
\hline
\end{tabular}

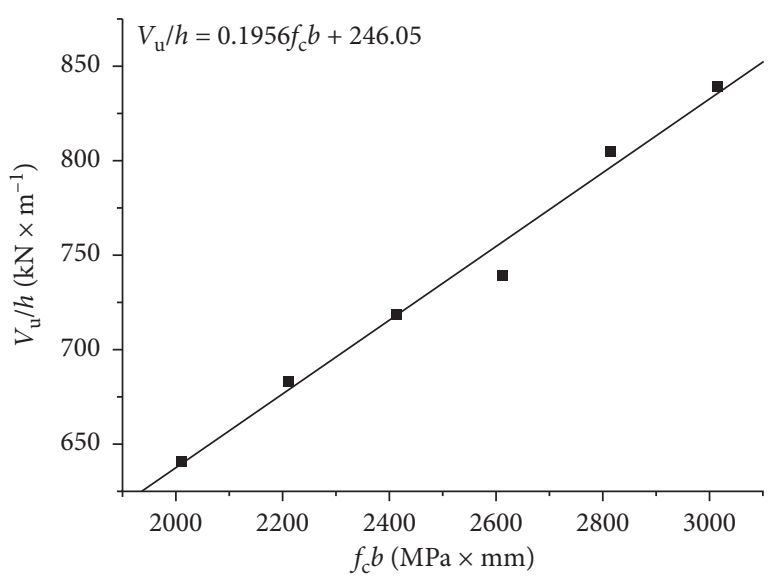

FIGURE 15: Fitting curve of concrete combination coefficient.

TABle 5: The parameters of the example.

\begin{tabular}{cccccc}
\hline$f_{\mathrm{c}}(\mathrm{MPa})$ & $b(\mathrm{~mm})$ & $h(\mathrm{~mm})$ & $f_{\mathrm{ys}}(\mathrm{MPa})$ & $t(\mathrm{~mm})$ & $V_{\mathrm{u}}(\mathrm{kN})$ \\
\hline & & & & 6 & 335.63 \\
& & & & 8 & 366.83 \\
20.1 & \multirow{2}{*}{150} & \multirow{2}{*}{400} & \multirow{2}{*}{235} & 10 & 385.78 \\
& & & & 12 & 396.35 \\
& & & & 14 & 412.68 \\
& & & & 16 & 438.32 \\
\hline
\end{tabular}

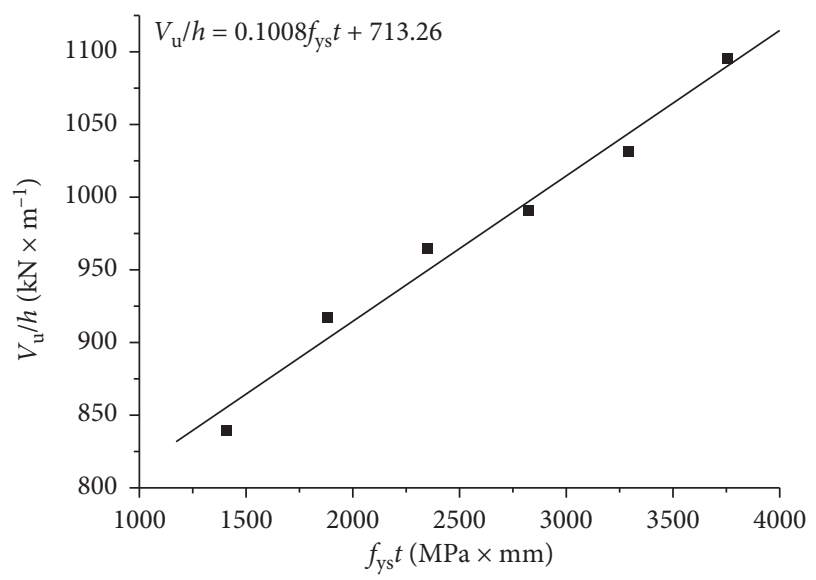

Figure 16: Fitting curve of steel plate combination coefficient.

indicated that this shear bearing capacity could provide references to the design and application of steel plateconcrete composite slab.
TABLE 6: Comparison of formula in this paper with test results.

\begin{tabular}{lccccccc}
\hline Specimens & $\begin{array}{c}b \\
(\mathrm{~mm})\end{array}$ & $\begin{array}{c}t \\
(\mathrm{~mm})\end{array}$ & $\begin{array}{c}P_{j} \\
(\mathrm{kN})\end{array}$ & $\begin{array}{c}V_{\mathrm{u}} \\
(\mathrm{kN})\end{array}$ & $\begin{array}{c}P_{\mathrm{R}} \\
(\mathrm{kN})\end{array}$ & $V_{\mathrm{u}} / P_{j}$ & $P_{\mathrm{R}} / P_{j}$ \\
\hline SCS-1 & 150 & 6 & 344.32 & 343.61 & 336.55 & 1.0 & 0.98 \\
SCS-2 & 165 & 6 & 416.88 & 416.18 & 408.57 & 1.0 & 0.98 \\
SCS-3 & 150 & 6 & 304.36 & 303.74 & 299.43 & 0.98 & 0.98 \\
\hline
\end{tabular}

\section{Conclusions}

Experimental studies and numerical analyses were used to investigate the shear load-carrying capacity, deformation, and crack development in steel plate-concrete composite slab, as well as the effects of the shear span ratio and shear stud spacing on the shear performance and the contribution of the steel plate and the concrete to the shear performance. A rotational crack model based on the modified compression field theory developed by UMAT (user material) of ABAQUS software was proposed and applied to the nonlinear analysis, and a numerical simulated model for the steel-concrete composite slab was built for shear analysis. The following main conclusions can be obtained:

(a) The failure modes of the steel plate-concrete composite slabs in shear included bending failure and shear-compression failure. Bending failure was primarily witnessed in the shear span ratio of equal or greater than 2.63, whereas shear-compression failure was the main mode of shear failure for the composite slabs.

(b) The shear force sustained by the concrete ranged from approximately $37 \%$ to $47 \%$, and the steel plate contributed more than $50 \%$ of the shear capacity. As shown by comparison of SCS- 1 and SCS-2, the ultimate shear capacity decreased by $21 \%$ as the shear span ratio increased from 1.88 to 2.63 . Furthermore, as shown by comparison of SCS- 2 and SCS-3, the ultimate shear capacity decreased by $27 \%$ as the shear stud spacing increased from $150 \mathrm{~mm}$ to $250 \mathrm{~mm}$. The actual shear force sustained by the concrete in the composite slab was 1.27 to 2.22 times greater than that of the calculated value through the Chinese Design Code for Concrete Structures (GB 50010-2010). Moreover, the load-carrying capacity of the concrete with smaller shear stud spacing was 1.75 times higher than that of the concrete with $250 \mathrm{~mm}$ shear stud spacing, but the shear stud spacing did not significantly affect the failure mode of the specimen.

(c) Bending failure was witnessed in the plain concrete slab specimen. After the combination of the steel plate and the resultant formation of the composite slab, the mode of failure changed to shear failure. The shear force sustained by the steel plate in the composite slab comprised more than $50 \%$ of the ultimate shear capacity, and the shear force sustained by the concrete doubled more than the calculated shear value according to the Chinese standard, suggesting that the 
presence of the steel plate significantly improved the shear capacity of the member.

(d) The modified compression field theory was used for the secondary development and establishment of the numerical model for shear analysis. The ultimate shear capacity of the composite slab acquired through the numerical analysis corresponded with the experimental values and surpassed the performance of the traditional fixed crack model. Thus, the proposed finite element numerical model for shear analysis would be capable of simulating the practical shear softening of concrete.

(e) The shear capacity of steel plate-concrete composite slabs was mainly affected by three factors: steel plate thickness $t$, concrete thickness $b$, and section height $h$ through parameter analysis. Based on shear bearing capacity formula of ordinary reinforced concrete beams, a general formula of shear bearing capacity of steel plate-concrete composite slabs was obtained. The results of the formula agreed with the test result, which could provide references to the design and application of steel plate-concrete composite slab.

\section{Data Availability}

The data used to support the findings of this study are included within the article.

\section{Conflicts of Interest}

The authors declare that they have no conflicts of interest.

\section{Acknowledgments}

The authors gratefully acknowledge the financial support provided by the National Natural Science Foundation of China (nos. 51278488 and 51678564) and open projects of State Key Laboratory of Coal Resources and Safe Mining, China University of Mining (no. SKLCRSM14KFB05).

\section{References}

[1] C. S. Cai, J. Nie, and X. M. Shi, "Interface slip effect on bonded plate repairs of concrete beams," Engineering Structures, vol. 29, no. 6, pp. 1084-1095, 2007.

[2] J. Zhao, "Experimental and theoretical research on flexural strengthening of RC beams using steel plate-concrete composite technique," M.D. thesis, Tsinghua University, Beijing, China, 2008, in Chinese.

[3] H. D. Wright and S. C. Gallocher, "The behaviour of composite walling under construction and service loading," Journal of Constructional Steel Research, vol. 35, no. 3, pp. 257-273, 1995.

[4] R. A. Link and A. E. Elwi, "Composite concrete-steel plate walls: analysis and behavior," Journal of Structural Engineering, vol. 121, no. 2, pp. 260-271, 1995.

[5] J.-G. Nie, X.-W. Ma, M.-X. Tao, J.-S. Fan, and F.-M. Bu, "Effective stiffness of composite shear wall with double plates and filled concrete," Journal of Constructional Steel Research, vol. 99, pp. 140-148, 2014.

[6] S. A. A. Hosseinzadeh and M. Tehranizadeh, "Behavioral characteristics of Code designed steel plate shear wall systems," Journal of Constructional Steel Research, vol. 99, pp. 72-84, 2014.

[7] J. G. Nie, L. L. Wu, J. S. Fan et al., "Preliminary study of channel steel-concrete composite beam and application," China Civil Engineering Journal, vol. 41, no. 11, pp. 78-85, 2008, in Chinese.

[8] L. Wu, J. Nie, J. Lu, J. Fan, and C. S. Cai, "A new type of steelconcrete composite channel girder and its preliminary experimental study," Journal of Constructional Steel Research, vol. 85, pp. 163-177, 2013.

[9] M. Takeuchi, M. Narikawa, K. Hara, and S. Usami, "Study on a concrete filled structure for nuclear power plants," Nuclear Engineering and Design, vol. 179, no. 2, pp. 209-223, 1998.

[10] Q. Q. Liang, B. Uy, and M. A. Bradford, "Local buckling of steel plates in double skin composite panels under biaxial compression and shear," Journal of Structural Engineering, vol. 130, no. 3, pp. 443-451, 2004.

[11] A. H. Varma, S. R. Malushte, K. C. Sener, and Z. Lai, "Steelplate composite (SC) walls for safety related nuclear facilities: design for in-plane forces and out-of-plane moments," $\mathrm{Nu}$ clear Engineering and Design, vol. 269, pp. 240-249, 2014.

[12] A. Arabzadeh, M. Soltani, and A. Ayazi, "Experimental investigation of composite shear walls under shear loadings," Thin-Walled Structures, vol. 49, no. 7, pp. 842-854, 2011.

[13] A. Arabzade, H. Moharami, and A. Ayazi, "Local elastic buckling coefficients of Steel Plates in composite steel plate shear walls," Scientia Iranica, vol. 18, no. 1, pp. 9-15, 2011.

[14] K. Zhang, A. H. Varma, S. R. Malushte, and S. Gallocher, "Effect of shear connectors on local buckling and composite action in steel concrete composite walls," Nuclear Engineering and Design, vol. 269, pp. 231-239, 2014.

[15] Y. Yang, J. B. Liu, J. S. Fan et al., "Experimental study on flexural capacity of steel plate-concrete composite slabs," Journal of Building Structures, vol. 34, no. 10, pp. 24-31, 2013, in Chinese.

[16] F. J. Vecchio and M. P. Collins, "The modified compressionfield theory for reinforced concrete elements subjected to shear," ACI Journal Proceedings, vol. 83, no. 2, pp. 219-231, 1986.

[17] M. P. Collins, "Towards a rational theory for RC members in shear," ASCE Journal of the Structural Division, vol. 104, no. ST4, pp. 649-666, 1987.

[18] D. Mitchell and M. P. Collins, "Diagonal compression field theory-A rational model for structural conerete in pure torsion," ACI Joumal Proceedings, vol. 71, no. 8, pp. 396-408, 1974.

[19] R. R. H. Zhu, T. T. C. Hsu, and J.-Y. Lee, "Rational shear modulus for smeared-crack analysis of reinforced concrete," ACI Structural Journal, vol. 98, no. 4, pp. 443-450, 2001.

[20] J. G. Ollgaard, R. G. Slutter, and J. W. Fisher, "Shear strength of stud connections in light weight and normal weight concrete," Journal of American Institute of Steel Construction, vol. 8 , no. 4 , pp. 55-64, 1971. 


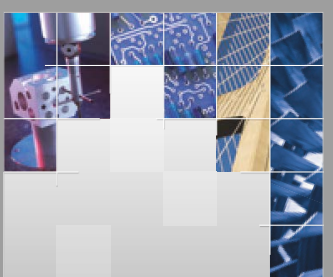

\section{Enfincering}
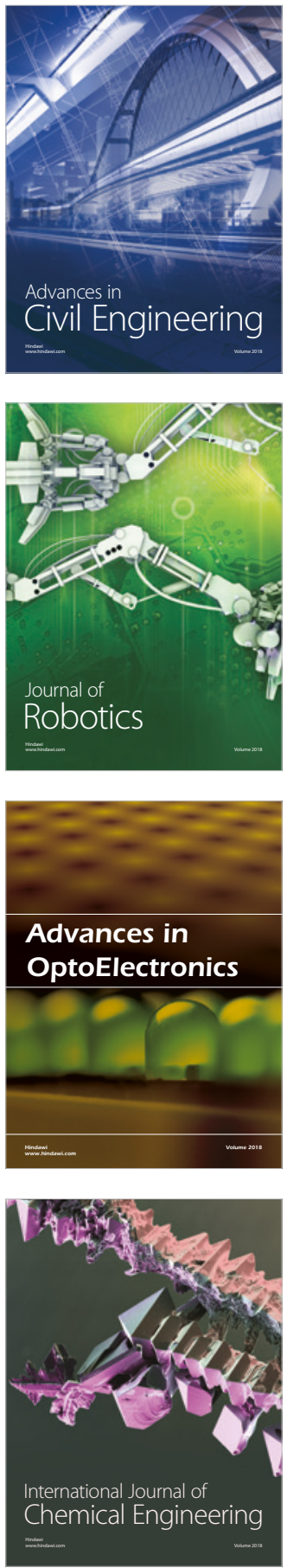

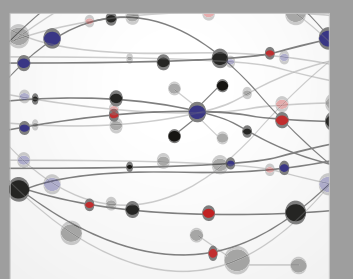

\section{Rotating \\ Machinery}

The Scientific World Journal

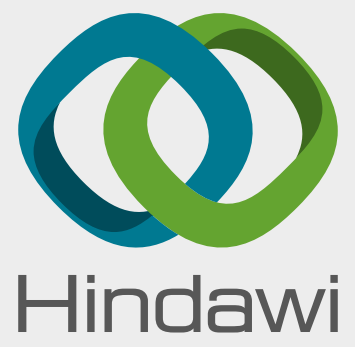

Submit your manuscripts at

www.hindawi.com
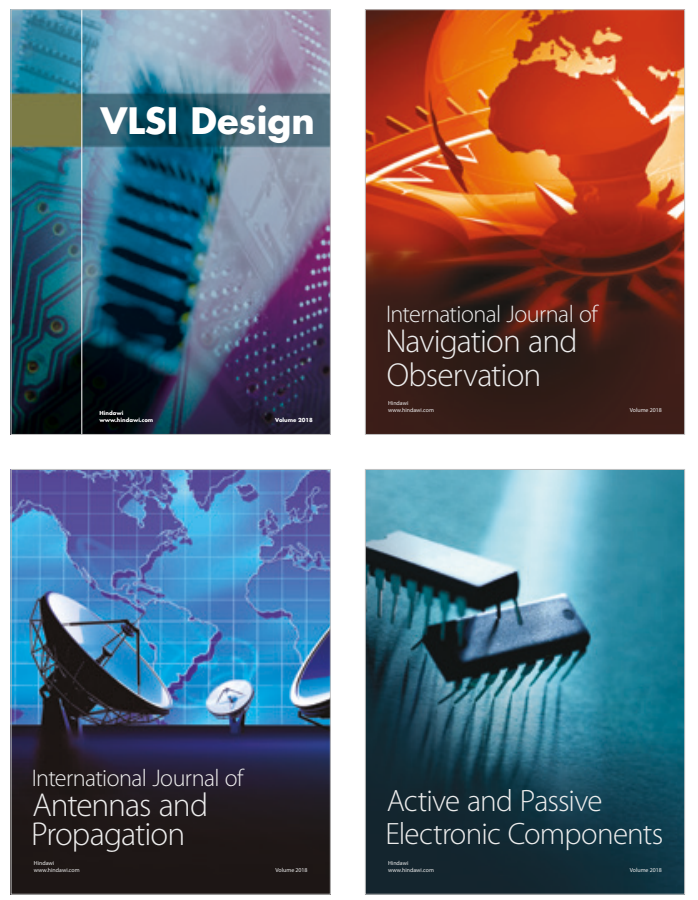
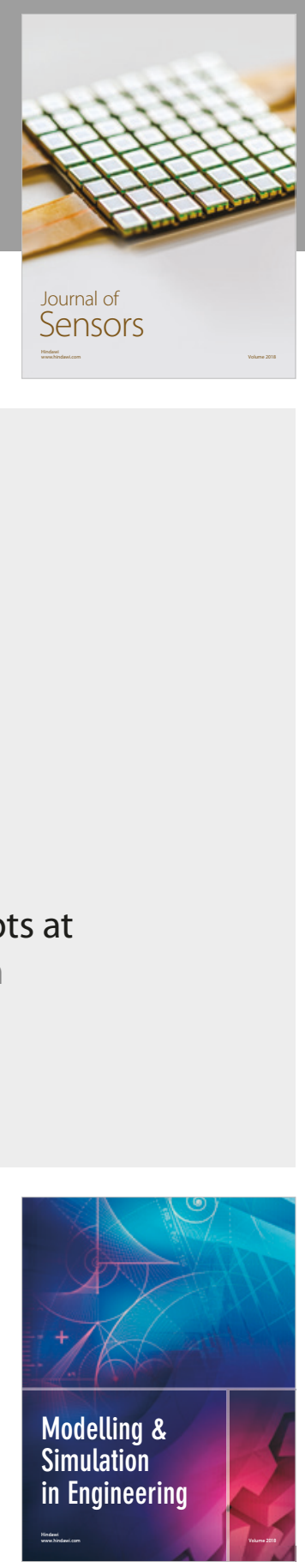

\section{Advances \\ Multimedia}
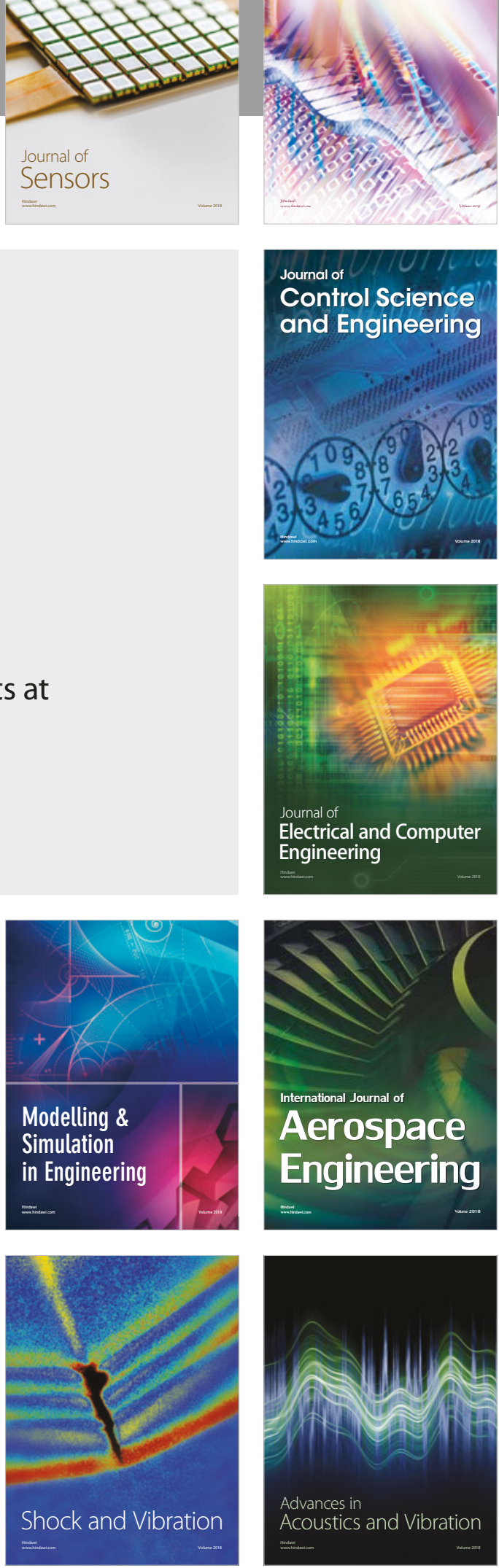